\title{
Prevenção de cárie dentária e doença periodontal em Ortodontia: uma necessidade imprescindível
}

\author{
Kelly Polido Kaneshiro Olympio*, Priscila Ariede Petinuci Bardal*, José Fernando Castanha Henriques**, \\ José Roberto de Magalhães Bastos**
}

\begin{abstract}
Resumo
O tratamento ortodôntico envolve procedimentos, geralmente, realizados durante um longo período. No ato da remoção do aparelho, freqüentemente, são encontradas áreas de desmineralização sob braquetes e bandas, quando já não há cavitações e, na maioria das vezes, inflamações dos tecidos periodontais. Para evitar estas iatrogenias, o clínico geral ou o especialista e toda sua equipe devem estar realmente motivados e envolvidos na aplicação dos conceitos de Odontologia Preventiva em seus pacientes ou, pelo menos, dispostos a delegar esta tarefa a alguém capacitado para fazê-la. Existem métodos relativamente simples para se avaliar o potencial de colaboração do paciente com o tratamento proposto, antes mesmo de seu início, e de se manter este paciente em níveis aceitáveis de saúde bucal. A utilização de recursos áudiovisuais para motivar os pacientes, os reforços positivos, a realização de escovação supervisionada e da limpeza interdentária, orientação sobre higiene, manutenção de saúde bucal e dieta, utilização de diferentes tipos de acessórios ortodônticos e de agentes cimentantes, além do uso, quando necessário, de diversos métodos químicos, são importantes instrumentos a serem utilizados durante o tratamento ortodôntico. Tomando-se as devidas precauções, é possível alcançar uma oclusão funcional e esteticamente aceitável sem deixar que a doença tenha um papel coadjuvante no transcorrer e após o término do tratamento ortodôntico.
\end{abstract}

Palavras-chave: Ortodontia. Cárie dentária. Controle da placa. Prevenção.

\section{INTRODUÇÃO}

O século XX marcou a história da saúde bucal com a redução extraordinária na ocorrência de cárie dentária desde o início da década de 70 . A fluoretação das águas de abastecimento público, a adição de flúor nos dentifrícios, as alterações no padrão de consumo de açúcar, a melhora da higiene pessoal, incluindo a escovação, e o maior acesso à informação e à educação foram fatores essenciais para o declínio da prevalência de cárie nas últimas décadas.

Assim, devido a este fato, a população passou a perder menos dentes. Anteriormente a este quadro, havendo ausências dentárias e, com a pressão exercida pelos lábios, língua e bochechas sobre os dentes, dava-se o alinhamento natural daqueles elementos anteriormente apinhados. Hoje, em pleno século XXI, isto não mais ocorre e, com a

* Mestre em Odontologia em Saúde Coletiva, Aluna de Doutorado em Saúde Pública da Faculdade de Saúde Pública, Universidade de São Paulo.

** Professores Titular do Departamento de Odontopediatria, Ortodontia e Saúde Coletiva, Faculdade de Odontologia de Bauru, Universidade de São Paulo. 
miscigenação racial presente no Brasil e a melhora na utilização de métodos preventivos, o apinhamento dentário tornou-se, não raro, um problema estético e oclusal comum.

Almejando conquistar este crescente mercado, cirurgiões-dentistas mais desavisados se concentram no tratamento ortodôntico, esquecendo-se de possíveis iatrogenias que o mesmo possa provocar. Os acessórios ortodônticos colados nas superfícies dentárias dificultam a higienização e funcionam como retentores adicionais de placa bacteriana, levando a desmineralizações do esmalte, causando manchas brancas, cáries dentárias e gengivites. A rotina com que estas iatrogenias se apresentam só ocorre devido ao despreparo prévio dos pacientes antes da instalação do aparelho ortodôntico e da falta de reforço e motivação durante o tratamento.

O paciente ortodôntico não precisa se conformar com a condição de que pequenas desmineralizações e gengivites sejam o preço de um sorriso funcional e esteticamente aceitável. Com o conhecimento sobre métodos preventivos e com a importância que a Odontologia em Saúde Coletiva vem ganhando entre as especialidades odontológicas não se pode mais admitir que isto continue acontecendo.

Antes de se curar uma patologia é necessário que se mantenha a saúde do indivíduo e, para isto, existem instrumentos simples de serem utilizados como orientação de escovação e escovação supervisionada, uso correto do fio dental, bochechos com soluções de fluoreto de sódio, cloreto de cetilpiridínio, gluconato de clorexidina, aplicações tópicas de gel de clorexidina e flúor gel, colagem dos acessórios ortodônticos com adesivos que liberem fluoretos e, por fim, orientação da dieta, levando-se em conta os hábitos alimentares e a condição social e econômica do paciente.

A terapia ortodôntica não deve ter como meta final somente o estabelecimento de uma oclusão funcional e esteticamente aceitável. O longo período em que o paciente ortodôntico permanece sob tratamento é tempo mais do que necessário para que o profissional consiga motivar seu paciente quanto a mudanças de comportamento, resultando na escolha de hábitos mais saudáveis. Assim, o sucesso do tratamento ortodôntico está em corrigir a oclusão da maneira mais satisfatória possível sem, contudo, alterar a higidez pré-existente dos dentes e tecidos de suporte, necessitando para isto, aplicar um modelo de programa educativo-preventivo individualizado a cada paciente, considerando suas características de risco à cárie dentária, doença periodontal e seu potencial de colaboração com as medidas empregadas.

\section{CONSIDERAÇÕES GERAIS}

\section{Importância e protocolo de programas educa- tivo-preventivos}

O controle de doenças durante a terapia ortodôntica já era discutido, desde 1977, por Alexander, Jacobs e Turpin ${ }^{1}$. Durante o tratamento ortodôntico, os profissionais têm uma excelente oportunidade de ensinar Odontologia Preventiva e controle de doenças aos seus pacientes, vendo-os regularmente, por um prolongado período de tempo, quando a maioria dos pacientes se encontra em uma idade de sensibilidade para o aprendizado e formação de hábitos.

Os autores ${ }^{1}$ concluíram que a repetição é uma parte importante do processo de aprendizagem. O conceito de controle de doenças é difícil de ser assimilado por alguns pacientes. O profissional não pode desestimular-se quando o paciente parece desinteressado, mas deve usar a criatividade para desenvolver novos métodos que satisfaçam as necessidades individuais.

Segundo Heintze ${ }^{22}$, inegavelmente, um tratamento com aparelhos fixos é uma intervenção considerável no ambiente da cavidade bucal. Os acessórios ortodônticos constituem a base para um risco elevado de cárie dentária e periodontite. Assim sendo, o ortodontista passa a ter a obrigação de reconhecer os riscos aos tecidos dentários e do 
periodonto e de atenuá-los com medidas adequadas. O ortodontista e sua equipe não devem deixar de almejar uma higiene bucal correta, de identificar pacientes com alto risco e, principalmente, de tratá-los oferecendo uma profilaxia intensiva.

Para que os danos nos tecidos sejam mínimos durante um tratamento ortodôntico, os seguintes pressupostos deveriam ser observados ${ }^{20}$ : baixo risco de periodontite; baixo risco de cárie; instrução e motivação do paciente; sistema de acompanhamento eficiente.

Se qualquer um desses tópicos não for atendido, o ortodontista não deve começar o tratamento com aparelhos fixos e, sim, adiá-lo pelo tempo necessário, até que essas exigências sejam alcançadas. Se a higiene bucal do paciente piorar muito durante o tratamento, sejam quais forem as razões, ou se houver o estabelecimento de extensivas destruições periodontais, o ortodontista deve ter a coragem de interromper o tratamento.

A remoção profissional da placa dentária é considerada como a garantia para o sucesso da profilaxia individual. É recomendável usar pequenas taças de borracha junto com uma pasta profilática. A remoção completa dentro de um curto espaço de tempo (cerca de 4 minutos) pode ser alcançada com os aparelhos tipo Air-flow ou Prophy-Jet.

O paciente com aparelhos fixos tem que cuidar de seus dentes atenciosamente, pois a higiene bucal, nestes casos, é difícil. Enquanto a região problemática nos dentes com bandas está localizada no lado cervical da banda; nos dentes com braquetes, as superfícies críticas são aquelas nos lados mesial e distal da base do braquete. Estas superfícies estão localizadas na "sombra" do arco e são de difícil acesso para as cerdas da escova. Por isso, os fabricantes de escovas dentárias oferecem escovas especiais com cerdas reduzidas no centro da cabeça da escova. Se o paciente aplicar a técnica correta e se ele exercer a pressão suficiente, essas escovas especiais não apresentam vantagem com respeito ao efeito de limpeza, comparandose com as escovas normais. Para limpar as áreas proximais é adequado usar o fio dental especial Superfloss, cuja ponta endurecida pode penetrar debaixo do arco, atingindo a área proximal ${ }^{22}$.

$\mathrm{Na}$ opinião do autor ${ }^{22}$, deve-se explicar aos pais sobre a dieta. Uma dieta variada, com pouco açúcar, não somente produz efeitos positivos nos dentes, mas também um desenvolvimento saudável do próprio organismo. Quanto à instrução de higiene bucal, seria aconselhável e ajudaria na motivação, assim como na compreensão da correlação entre a higiene bucal e o acúmulo de placa, limpar profissionalmente um dente antes de colocar o evidenciador de placa. Depois da aplicação do evidenciador, somente um dente ficaria sem o líquido corante.

Nos pacientes com aparelho fixo, uma limpeza perfeita dos dentes demora, pelo menos, dez minutos. Isso exige do paciente muito cuidado e disciplina, o que deve ser esclarecido já no início do tratamento. A motivação para alcançar este objetivo deve ser constante. Isto significa que a cada terceira ou quarta consulta ortodôntica deve ser programado tempo suficiente para o seguinte programa de acompanhamento: avaliação do risco à cárie; avaliação do grau de inflamação da gengiva; aplicação de um verniz de clorexidina e flúor em volta das bases dos braquetes e tratamento das superfícies desmineralizadas com flúor ${ }^{22}$.

Os intervalos para o programa de acompanhamento dependem do risco atual à cárie dentária. Eles podem compreender um mês ou, no máximo, quatro meses.

A prevenção básica é composta pela execução dos seguintes procedimentos: higiene bucal com dentifrício fluoretado, escova interproximal e fio dental Superfloss; remoção profissional da placa; aplicação do verniz de clorexidina nas superfícies de risco (2-4 vezes ao ano); fortalecimento da conscientização sobre dieta adequada.

É importante sensibilizar o paciente em relação à sua própria boca, despertando o seu interesse pela saúde bucal e, assim, proporcionar a prevenção adequada da cárie dentária e da gengivite. 
Mas isto exige muita paciência, tanto do paciente quanto da equipe que o trata. Com este acompanhamento intenso, o ortodontista tem a grande chance de orientar os pacientes, muitas vezes jovens, no que tange a saúde bucal. Isso pode propiciar efeitos duradouros que continuarão após o tratamento ortodôntico ${ }^{22}$.

Bacchi, Prates e Attizzani² fizeram uma revisão bibliográfica sobre os principais procedimentos preventivos que o paciente ortodôntico deve adotar e comentaram sobre os seguintes tópicos:

\section{Dieta}

O paciente ortodôntico, na sua maioria situado em faixa etária jovem, comumente propícia a alto consumo de hidratos de carbono, deve ser alertado quanto à dieta. $\mathrm{O}$ paciente e os pais devem ser orientados a respeito da importância de se restringir o consumo de alimentos tidos como cariogênicos. Aconselha-se que a ingestão desse tipo de alimento deva ser feito em ocasiões programadas e, preferencialmente, restritas às refeições principais como café da manhã, almoço e jantar.

Deve-se evitar a ingestão freqüente de alimentos para se permitir a ação salivar natural de remineralização superficial do esmalte, uma vez que o $\mathrm{pH}$ mantido constantemente baixo desestabiliza a hidroxiapatita, criando áreas de desmineralização. O aparelho ortodôntico, sem sombra de dúvidas, funciona como um retentor de placa bacteriana e o controle dietético é um meio essencial de se evitar o seu acúmulo freqüente e, especialmente, a composição da placa.

A dieta é um dos principais fatores que influenciam no desenvolvimento de cárie dentária; assim é fundamental a realização da avaliação dietética. Isso deverá ser feito em pacientes com alta atividade de cárie ou com padrão de cárie incomum ${ }^{6}$.

\section{Escovação}

A primeira escovação dentária diária para o paciente ortodôntico, por uma questão de padronização e disciplina, deve ser preconizada antes e após o café da manhã. Antes, porque à noite reduz-se o fluxo salivar e com isto a capacidade tampão da saliva bem como sua propriedade imunizadora diminui e, após, para a remoção de resíduos fermentáveis pela ação bacteriana e capazes de produzir desestabilização da apatita. É importante que a escovação ocorra imediatamente após a ingestão de alimentos, uma vez que o $\mathrm{pH}$ torna-se crítico, isto é, atinge um grau de acidez capaz de solubilizar a hidroxiapatita, em poucos minutos. A escovação é um dos principais meios mecânico-profiláticos e, por isto, deve ser corrigida e melhorada sempre que necessário. Torna-se interessante a adoção de um método de auto-aferição (realizado pelo próprio paciente) através do uso de pastilhas ou soluções evidenciadoras de placa bacteriana, para que se motive o paciente a obter, por si mesmo um bom índice de higiene bucal. O objetivo da escovação não deve ser apenas o cumprimento mecânico e automático de um mero ritual cosmético, mas sim a remoção consciente e eficiente de todo o conteúdo residual formador de placa bacteriana que possa estar aderido aos dentes, aparelhos e sulcos gengivais. Fazer o paciente ortodôntico entender claramente estes aspectos e torná-lo motivado para dar a devida atenção a estes cuidados não são tarefas fáceis, mas necessárias.

\section{Fio ou fita dental}

O ortodontista deve preconizar o uso de fio ou fita dental para limpeza dos espaços proximais interdentários, como medida de grande valia para complementação da higiene bucal. Com o auxílio de "passadores" de fio comercialmente produzidos ou então confeccionados com fio ortodôntico, o paciente poderá complementar a remoção da placa acumulada em regiões de difícil acesso para a escovação. Os métodos mecânicos de higiene bucal, utilizados domesticamente, ou seja, a escova e o fio dental, parecem ser os de maior eficiência e importância nos cuidados profiláticos cotidianos e, portanto, o paciente deve ser conscientizado a respeito de sua importância. 
Afora estes procedimentos rotineiros, os demais são meramente complementares e de adoção até facultativa. Por uma questão de comodismo e conveniência, muitas vezes, alguns pacientes insistem em fazer uso rotineiro de dispositivos jateadores de água, atribuindo a este método uma importância que, na verdade, não possui, muito embora seus fabricantes, obviamente, ressaltemna. Faz-se necessário desmistificar certas condutas e métodos que, às vezes, são divulgações meramente comerciais. $\mathrm{O}$ uso adequado da escova e fio dental é, na verdade, suficiente para a remoção satisfatória da placa bacteriana ${ }^{2}$.

Souza, Falcão e Araújo ${ }^{31}$ fizeram uma proposta de orientação para higiene bucal em pacientes ortodônticos. Os autores afirmaram que o importante é remover a placa dentária, independentemente de como o paciente atinja este objetivo. Um outro aspecto a ser considerado é que a experiência anterior do indivíduo nunca deve ser desprezada, durante um processo educativo. Deste modo, todo o esforço do profissional, no sentido de instruir bons hábitos de higiene para a maioria dos pacientes, em especial o paciente ortodôntico, está sedimentado nesta visão e obedece aos seguintes passos: 1) informações sobre placa dentária e seu significado clínico; 2) revelação de placa dentária e demonstração das áreas coradas; 3 ) o paciente recebe uma escova macia e é convidado a remover a placa corada em frente ao espelho sob supervisão do profissional. Neste momento, as dificuldades do paciente já são observadas. É recomendável que a escova, inicialmente, não contenha creme dental para facilitar a visualização de áreas que necessitem de maior atuação; em seguida, usar a escova com dentifrício fluoretado. Quando a escovação é dada como concluída, o paciente enxágua a boca e, junto com o profissional, avalia os resultados. 4) Concluída a escovação, chama-se a atenção para a presença de placa nos espaços interproximais, destacando a importância de se adotar o uso do fio dental como método também essencial para uma completa higiene. Dependendo dos resulta- dos, verifica-se a necessidade de instituir-se uma orientação padrão ou de apenas corrigir as imperfeições.

\section{Agentes químicos}

Flúor

Geiger et al. ${ }^{19}$ conduziram um estudo clínico para determinar se a freqüência de bochechos com fluoreto de sódio $0,05 \%$ influenciava na formação de lesões de mancha branca do esmalte em pacientes que utilizavam braquetes ortodônticos. Participaram deste estudo pacientes de duas clínicas ortodônticas privadas. Cada um recebeu instruções de cuidados caseiros e foram instruídos a bochecharem $10 \mathrm{ml}$ de fluoreto de sódio diariamente, antes de irem dormir. O bochecho foi fornecido gratuitamente para determinar se isto afetava a colaboração com a prescrição de uso. A colaboração foi medida pelo registro do número de vidros do produto utilizados pelo paciente. Como avaliação do estado de higiene bucal, foram registradas lesões de mancha branca, no momento da descolagem dos braquetes. Somente 13\% dos 206 participantes cooperaram completamente com o protocolo de bochechos; 425 pacientes usaram $10 \mathrm{ml}$, aproximadamente, um dia sim, um dia não, e $45 \%$ fizeram o bochecho ainda menos freqüentemente. Foi concluído que uma redução significante de lesões de manchas brancas no esmalte pode ser alcançada durante o tratamento ortodôntico através do uso de $10 \mathrm{ml}$ de solução para bochecho à base de fluoreto de sódio neutro.

Heintze $^{22}$ afirmou que o flúor não deve somente ser considerado como uma substância preventiva contra a cárie, mas também como uma substância terapêutica que pode remineralizar as desmineralizações. Embora estudos controlados comprovem que a incidência de manchas brancas pode ser reduzida com bochechos de flúor, o ortodontista não deve confiar somente nos bochechos. Por um lado, o paciente não os realiza com regularidade; por outro, por causa dos elementos de retenção, eles não atingem, suficientemente, 
as superfícies dos dentes onde devem surtir efeitos, isto é, em volta das bases dos braquetes, nas margens das bandas e nas superfícies proximais. Além disso, o flúor dos bochechos é removido rapidamente pela saliva. Por este motivo, seria melhor utilizar vernizes de flúor que podem ser aplicados nas superfícies de risco, três ou mais vezes por ano, dependendo do grau de risco da cárie. Adicionalmente, deve-se aplicar um verniz de flúor nas superfícies, tanto antes da colocação das bandas ortodônticas, quanto durante o tratamento e na remoção dos acessórios.

\section{Clorexidina}

Brightman et al. ${ }^{7}$ realizaram um estudo para avaliar a efetividade de uma solução para bochecho de gluconato de clorexidina $0,12 \%$, Peridex $(\mathrm{CH})$, em pacientes ortodônticos de 11 a 17 anos de idade com gengivite estabelecida. Trinta e quatro pacientes foram divididos em dois grupos $(\mathrm{CH}$ e placebo) de 17 pacientes cada. Estes pacientes foram avaliados inicialmente, após 6 semanas e após doze semanas em um estudo duplo-cego. Os resultados mostraram reduções: de $64,9 \%$ do indice de placa, $61 \%$ do índice gengival e $77,2 \%$ do sangramento gengival naqueles pacientes que fizeram uso do Peridex. Os autores concluíram que o Peridex, em combinação com a remoção mecânica da placa, provou ser um importante agente terapêutico no controle da inflamação gengival, sangramento e acúmulo de placa em pacientes ortodônticos de 11 a 17 anos de idade com gengivite estabelecida.

Segundo Heintze ${ }^{22}$, quando é detectada uma alta contagem de $S$. mutans, o tratamento antibacteriano com clorexidina é indicado. Para diminuir o número de $S$. mutans das superfícies dentárias, de uma maneira eficiente e duradoura, um gel de clorexidina $1 \%$ gera bons resultados. Este gel é aplicado através de moldeiras flexíveis individuais. Mas uma única aplicação não se mostra eficiente. Foi observado que, na maioria dos pacientes, o gel deve ser aplicado seis vezes durante dois dias, para alcançar o objetivo do tratamento. O paciente é orientado a fazer movimentos de mastigação com as moldeiras (cobertas de gel), durante cinco minutos, para que o gel seja, então, bem difundido, penetrando nas áreas proximais e nas fissuras. Entre as aplicações deve-se, meticulosamente, enxaguar as moldeiras com água. Como alternativa, o próprio paciente pode aplicar o gel nas moldeiras, diariamente, durante um período de dez dias. Porém, deve-se atentar ao fato de que a escovação com gel de clorexidina é menos efetiva. A desvantagem deste procedimento, além de ser demasiadamente demorado, baseia-se no fato de que o paciente age fora do controle do ortodontista.

Foram lançados alguns vernizes que contêm clorexidina, como por exemplo, o EC 40 (Explore), com $40 \%$ de clorexidina na base de sandarac; o Chilorzoin (Kwwell), com 10\% de clorexidina e o Cervitec (Vivadent) que contém além de $1 \%$ de clorexidina, $1 \%$ de timol, o qual também gera efeitos antibacterianos. $\mathrm{O}$ verniz é aplicado somente nas superfícies de risco, ou seja, naquelas em volta das bases dos braquetes. Os vernizes oferecem a vantagem de liberar clorexidina durante um período prolongado. Assim, o tratamento deve ser repetido em intervalos definidos: no caso do Cervitec, pelo menos a cada três meses; no do EC 40, provavelmente duas vezes ao ano. Em um estudo no qual foi aplicado Chlorzoin quatro vezes antes da colagem dos braquetes, obteve-se como resultado, que mesmo depois de sete meses, os $S$. mutans não foram detectados em 11 dos 26 pacientes. No caso do verniz EC 40, uma única aplicação nas superfícies proximais pode ser suficiente para manter o nível de $S$. mutans até quatro meses abaixo daquele anterior ao tratamento. Nas fissuras, uma só aplicação pode eliminar os S. mutans junto a $50 \%$ dos pacientes; uma recolonização foi observada apenas depois de 22 semanas. No caso do Cervitec, no entanto, as superfícies dos dentes são recolonizadas mais rapidamente do que com o verniz EC 40. Antes da aplicação de qualquer verniz, a placa tem que ser removida e 
os dentes que estão sendo tratados devem ser secos. O verniz é aplicado com um pincel ou um cotonete sobre as superfícies de risco, em volta dos braquetes e nas áreas proximais e distribuído com jatos de ar e fio dental. Os vernizes EC 40 e Cervitec endurecem ao contato com a saliva. No caso do Chlorzoin, o verniz tem que ser fixado na superfície através de um adesivo de poliuretano. Muito cuidado deve ser tomado se for aplicado o EC 40. Como a concentração de clorexidina pode ser muito alta e pode causar irritações na gengiva, o contato com a gengiva deve ser evitado. Após a aplicação, o paciente não deve comer alimentos sólidos por quatro horas e não deve escovar os dentes por um dia para que se possa formar um depósito de clorexidina ${ }^{22}$.

\section{Cloreto de Cetilpiridínio}

Carvalho ${ }^{9}$ comparou a eficácia de métodos de higiene em pacientes ortodônticos, concluindo que a escovação associada a bochechos de Cepacol (solução de cloreto de cetilpiridínio 1:4000) parece ser uma conduta de higiene promissora em relação ao controle do índice de placa em pacientes portadores de aparelho ortodôntico fixo.

Pinheiro $^{24}$ avaliou o efeito de um colutório contendo cloreto de cetilpiridínio e fluoreto de sódio na fermentação e na síntese de polissacarídeos extracelulares insolúveis da placa dentária in vitro. A diluição 1:10 desta substância inibiu 96\% dos ácidos de fermentação e 100\% da síntese de polissacarídeos insolúveis. Considerando-se que a diluição utilizada normalmente em bochechos é $1: 2$, concluiu-se que este é um colutório bastante eficaz contra as bactérias da placa dentária.

Garib et al. ${ }^{18}$ avaliaram a eficácia de bochechos com solução de clorexidina $0,12 \%$ e cloreto de cetilpiridínio na redução da placa dentária e gengivite. Os resultados obtidos permitiram as seguintes conclusões: a) os bochechos empregados levaram a uma redução do índice de placa e de sangramento gengival estatisticamente significante nos três grupos experimentais. No entanto, não hou- ve diferença estatisticamente significante entre os grupos; b) o cloreto de cetilpiridínio isoladamente levou a uma redução do índice de placa e do sangramento gengival de $23,6 \%$ e $55,9 \%$, respectivamente, enquanto que associado à clorexidina levou a uma redução de $52,2 \%$ no índice de placa e de $62,9 \%$ no índice de sangramento. Constatou-se que a redução do índice de placa foi maior para os pacientes colaboradores, quando comparados aos não colaboradores.

\section{Agentes cimentantes}

De acordo com Silva Filho et al. ${ }^{28}$, o papel desempenhado pelos cimentos de ionômero de vidro na prevenção da integridade do esmalte dentário tem contribuído para a construção de uma Ortodontia menos iatrogênica, motivo pelo qual passaram a ser sucessores dos cimentos até então usados para a cimentação de bandas e serão os prováveis sucessores das resinas convencionais usadas para a colagem direta.

Freitas ${ }^{17}$ publicou uma revisão de literatura sobre colagem de acessórios ortodônticos ao esmalte dentário, utilizando-se ionômero de vidro reforçado com resina. O autor verificou que o material é substituto eficiente e menos iatrogênico às resinas compostas, nas colagens, recolagens e retiradas do aparelho ortodôntico. A colagem dos aparatos ortodônticos pode ser feita em campo úmido e sem necessidade de condicionamento ácido no esmalte. O ionômero adere também ao metal e à porcelana e tem a capacidade de absorver flúor presente na cavidade bucal e liberá-lo gradativamente.

\section{DISCUSSÃO}

Face aos possíveis, e não raros, efeitos iatrogênicos causados pelo tratamento ortodôntico, a maioria dos autores ${ }^{1,2,13,14,16,21,22,27,29,30}$ concorda ser indispensável a instituição de métodos preventivos para todos os pacientes submetidos à terapia ortodôntica. É claro que o tipo, freqüência e quantidade das medidas adotadas para a implementação do programa dependerão das características 
individuais de ambas as partes - profissional e paciente. No que diz respeito ao profissional, há de se levar em conta seu modo de trabalho: se sabe aproveitar sua equipe no trabalho educacional e preventivo, se trabalha sozinho ou se prefere delegar esta atenção ao paciente a um profissional que só trabalhe com prevenção. Quanto ao paciente, há de se avaliar suas condições de saúde bucal e níveis de colaboração, bem como seu padrão de dieta. Geralmente, o tipo de dieta está relacionado com a condição social e com a ocupação do paciente. Assim, de acordo com Bastos, Henriques e Olympio $^{6}$, o profissional deve estar atento a esse fato quando fizer as orientações aos pacientes, incluindo orientação dietética.

É de responsabilidade do profissional motivar o paciente para que pratique uma higiene bucal eficaz, diariamente. Entretanto não é correto que o dentista assuma sozinho a responsabilidade da saúde bucal de seu paciente. O paciente deve entender que ele participa ativamente para o sucesso do tratamento ${ }^{25}$. Zachrisson ${ }^{32}$ enfatizou em seu trabalho que os ortodontistas não dão a merecida importância à motivação dos pacientes para higiene bucal e, na maioria dos casos, a adolescência seria a faixa etária mais propícia para o estabelecimento de bons hábitos de higiene bucal. A motivação é um processo subjetivo e de eficiência, nitidamente pessoal, cuja generalização torna-se impossivel. Assim, cada profissional tem a necessidade de descobrir qual o processo específico de motivação que funciona para cada caso, de modo a obter a melhor resposta de colaboração.

A importância de se instituir um programa de motivação e orientação para o controle mecânico da placa dentária é destacada por vários autores ${ }^{31,33,30}$, sendo que o método mais eficiente e simples para o controle da placa dentária se resume no uso da escova e do fio dental ${ }^{2}$. Heintze ${ }^{22}$ descreveu um interessante programa de prevenção para o paciente ortodôntico, analisando o paciente de forma global e considerando que os prejuízos de um tratamento ortodôntico interrompido por falta de colaboração do paciente e má higiene bucal podem ser menores do que as iatrogenias decorrentes em um caso como este.

Geiger et al. ${ }^{19}$, analisando programas educativos, avaliaram a necessidade de formar profissionais capazes de gerenciar ações educativas de modo que as orientações técnicas deixem de se sobrepor às ações, realmente capazes de promover mudanças comportamentais.

Puppin Filho et al. $^{26}$ relataram que há um maior risco de desenvolvimento de cárie dentária em pacientes que estão sob tratamento ortodôntico fixo. Há a necessidade da aquisição de métodos sistemáticos para minimizar esse risco, atuando desde a montagem e manejo clínico do aparelho pelo ortodontista até o controle da dieta e da higienização bucal por parte do paciente.

Em relação aos agentes cimentantes, Silva Fitho et al..$^{28}$ consideram que, ao agregar os cimentos de ionômero de vidro no seu arsenal, a Ortodontia passa a atacar a desmineralização do esmalte em duas vertentes: o regime de controle mecânico da placa bacteriana com um programa profilático e a liberação constante de flúor in locu, proveniente do material cimentante.

Os métodos químicos são de grande valia, principalmente em pacientes pouco colaboradores ou com higiene bucal deficiente. Os efeitos antiplaca da clorexidina e anticariogênicos do flúor são amplamente comprovados na literatura científi$\mathrm{ca}^{3,4,5,7,8,10,11,12,15,18,20,23}$. O cloreto de cetilpiridínio parece não atuar na gengivite estabelecida, mas na prevenção da mesma ${ }^{18}$.

Como visto, o número de pacientes que procuram tratamento ortodôntico cresce cada vez mais ${ }^{22}$. Hoje, os pacientes não assumem mais um papel de completa passividade, sujeitando-se a receber ordens sem entender o motivo, nem por que está sendo feito ${ }^{22}$. Tanto os pais quanto os pacientes querem fazer parte de todo o processo de decisão no que diz respeito à sua saúde. Neste aspecto, é dever do profissional alertar o paciente quanto à indicação ou contra-indicação do tratamento e 
sobre toda responsabilidade que o mesmo possui sobre a manutenção da própria saúde e sucesso do tratamento. Além disso, o ortodontista não pode ater-se apenas às correções estéticas e funcionais da oclusão. É necessário que todo um programa funcional e eficiente de educação e prevenção seja montado para que o paciente inicie o tratamento em condições de saúde e assim se mantenha, até além do período de contenção ortodôntica.

\section{CONCLUSÕES E RECOMENDAÇÕES}

- É possível que o paciente passe pelo tratamento ortodôntico sem sofrer danos iatrogênicos, bastando, para isto, que o mesmo seja inserido em um programa educativo-preventivo idealizado para este fim.

- O tratamento ortodôntico proporciona uma excelente oportunidade de se criar hábitos saudáveis nos pacientes, em função do tratamento geralmente se estender por um longo período de tempo, de maneira a prevenir doenças bucais, em razão das consultas de ativação e manutenção dos aparelhos.
- Se bem motivados, os pacientes podem receber benefícios além do período de tratamento, perpetuando as orientações recebidas, que devem se resumir na conscientização do paciente sobre sua responsabilidade frente à própria saúde e numa adequada conduta em higiene bucal.

- Para auxiliar na diminuição da quantidade de placa bacteriana, evitando cáries dentárias e gengivites, o profissional possui à sua disposição agentes químicos que funcionam como instrumentos auxiliares dos programas de prevenção para pacientes pouco colaboradores e com pobre higiene bucal. Estes agentes químicos podem ser usados com eficácia, antes mesmo do início do tratamento, para diminuir o número de microrganismos presentes, reduzindo riscos.

\title{
Prevention of dental caries and periodontal disease in Orthodontics: a indispensable necessity
}

\begin{abstract}
The orthodontic treatment involves proceedings, usually, made for a long time. At the moment of the appliance removal, desmineralizations have been often found under banded and bonded fittings, when there is no more cavitations and in the most of the times, neither periodontal tissue's inflamation. To avoid this iatrogenesis, the general clinician or the expert and his staff must be really motivated and involved on the application of Preventive Odontology concepts in their patients or, at least, disposed to delegate this important task to someone able to do it. There are simple methods to evaluate the potential of the patient's compliance with the proposed treatment, even before its beginning and keeping this patient under acceptable levels of oral health such as: visio-auditory resources, to motive the patients; positive reinforcements; supervisioned toothbrushing realization; interdental cleaning; hygiene, oral health and diet maintenance instructions; besides the use of several chemistry methods, when necessary, such as chlorexidine, fluoride and cetylpyridinium cloride, despite the fact of considering different kinds of orthodontics fittings and lutting agents. Taking the proper precautions, it's possible to reach an acceptable functional and esthetical occlusion without letting the disease has a supporting role during and after orthodontic treatment finishing.
\end{abstract}

Key words: Orthodontics. Dental caries. Periodontitis. Plaque control. Prevention. 


\section{REFERÊNCIAS}

1. ALEXANDER, C. M; JACOBS, J. D.; TURPIN, D. L. Disease control in an orthodontic practice. Am J Orthod, St. Louis, v. 71, no. 1, p. 79-93, Jan. 1977

2. BACCHI, E. O. S.; PRATES, N. S.; ATTIZZANI, A. Profilaxia bucodental em Ortodontia. RGO, Porto Alegre, v. 45, n. 6, p. 342-6, nov./dez. 1997.

3. BALL, D. M.; BALL JR., E. L. Comparative effectiveness of two mouthwashes used after gingivectomy. J Periodontol, Chicago, v. 38, no. 5, p. 395-7, Sept./Oct. 1967.

4. BARNES, G. P. et al. Effects of two cetylpyridinium chloride containing mouthwashes on bacterial plaque. J Periodontol, Chicago, v. 47, no. 7, p. 419-22, July, 1976

5. BARROS, W. M. R. et al. Efeito das diferentes concentrações de cloreto de cetilpiridínio na antisepsia do sulco gengival. Rev Fac Farm Odontol, Ribeirão Preto, v. 13, p. 115-26, 1976.

6. BASTOS, J. R. M.; HENRIQUES, J. F. C.; OLYMPIO, K. P. K. Manual de prevenção de cárie dentária e doença periodontal em pacientes sob tratamento ortodôntico. Bauru: Faculdade de Odontologia de Bauru, 2002.

7. BRIGHTMAN, L. J. et al. The effects of a $0,12 \%$ chlorhexidine gluconate mouthrinse on orthodontic patients aged 11 through 17 with estabilished gingivitis. Am J Orthod Dentofacial Orthop, St. Louis, v. 100, no. 4, p. 324-29, Oct. 1991

8. BUDTZ-JÖRGENSEN, E.; LÖE, H. Chlorexidine as a denture desinfetant in the treatment of denture stomatitis. Scand J Dent Res, Copenhagen, v. 80, p. 457-464, 1972.

9. CARVALHO, L. S. Estudo em pacientes portadores de aparelho ortodôntico, correlacionando os índices de placa e gengival à escovação dental com bochechos de fluoreto de sódio e com cloreto de cetilpiridínio. 1989. 107f. Tese (Doutorado)-Faculdade de Odontologia de São Paulo, Universidade de São Paulo, São Paulo, 1989

10. CASTELLANOS. N. N. Formulación de acetato de clorexidina como colutório. Rev Cub Farmacol, Cuba, v. 21, p. 95-101, 1987.

11. CHEYNE, V. D.; RICE, T. B. Effects of topically applied fluorine on human dental caries, including a method for its application. J Dent Res, Chicago, v. 21, no. 3, p. 320, 1942.

12. DE LA ROSA, M.; STURZENBERGER, O. P. Clinical reduction of gingivitie throught the use of a mouthwashcontaining two quaternary ammonium compounds. J Periodontol, Chicago, v. 47, no. 9, p. 535-7, 1976.

13. DENES, J.; GÁBRIS, K. Results of a 3-year oral hygiene programme including amine fluoride products in patients treated with fixedorthodontic appliances. Eur J Orthod, Oxford, v. 13, no. 2, p. 129-33, Apr. 1991.

14. DUBEY, R. JALILI, V. P. GARG, S. Oral hygiene and gingival status in orthodontic patients. J Pierre Fauchard Acad, Indore, v. 7 , no. 2, p. 43-54, June, 1993.

15. FEIST, I. S.; MICHELI, G.; SARIAN, R. Clorexidina: os prós e contras da sua utilização em periodontia. Rev APCD, São Paulo, v. 43, n. 1, p. 21-3, jan./fev. 1989.

16. FELIU, J. L. Long term benefits of orthodontic treatment on oral hygiene. Am J Orthod, St. Louis, v. 82, no. 6, p. 473-477, Dec. 1982.

17. FREITAS, P. C. Cimento ionômero de vidro como alternativa na colagem em Ortodontia. Ortodontia, São Paulo, v. 32, n. 3, p. 42-47, set./dez. 1999.

18. GARIB, D. G. et al. Efeito do uso de gluconato de clorexidina e do cloreto de cetilpiridínio em bochechos como meio complementar da higiene bucal em pacientes sob tratamento ortodôntico. Ortodontia, São Paulo, v. 30, n. 2, p. 22-30, mar./ago. 1997.

19. GEIGER, A. M. et al. Reducing white spot lesions in orthodontic populations with fluoride rinsing. Am J Orthod Dentofacial Orthop, St. Louis, v. 101, no. 5, p. 403-7, May, 1992.

20. GEIGER, M. A. et al. The effect of a fluoride program on white spot formation during orthodontic treatment. Am J Orthod
Dentofacial Orthop, St. Louis, v. 93, no. 1, p. 29-37, Jan 1988.

21. GERÔNIMO, D. H.; TOGASHI, A. Y.; HENRIQUES, J. F. Avaliação comparativa dos efeitos dos acessórios ortodônticos na saúde gengival e no índice de placa em pacientes com e sem orientação sobre métodos de higiene bucal. Ortodontia, São Paulo, v. 27, n. 3, p. 27-33, set./dez. 1994.

22. HEINTZE, S. D. A profilaxia individual em pacientes com apareIhos fixos - recomendações para o consultório. Ortodontia, São Paulo, v. 29, n. 2, p. 4-15, maio/ jun./jul./ago. 1996.

23. ITO, I. Y. et al. Efeitos do cloreto de cetilpiridínio na inibição da placa dentária e nas condições clínicas da gengiva humana. Odont Mod, [s.I.], v. 7, n. 2, p. 8-23, 1980

24. PINHEIRO, C. E. Efeito da associação do cloreto de cetilipiridínio- fluoreto de sódio na fermentação e na síntese de polissacarídeos extracelulares insolúveis da placa dentária "in vitro". Rev Bras Odontol, Rio de Janeiro, v. 48, n. 1, p. 18-20, 1991.

25. PRICHARD, J. F. Advanced periodontal disease: surgical and prothetic management. Philadelphia: Saunders, 1966. p. 3-44.

26. PUPPIN FILHO, A. et al. Controle da doença cárie em pacientes submetidos a tratamento ortodôntico. Rev Bras Odontol, Rio de Janeiro, v. 59, n. 4, p. 267-271, jul./ago. 2002.

27. SCHWANINGER, B.; SCHWANINGER, N. V. Developing na effective oral hygiene program for the orthodontic patient: review, rationale and recommendations. Am J Orthod, St. Louis v. 75 , no. 4, p. 447-452, Apr. 1979.

28. SILVA FILHO, O. G. et al. Avaliação clínica da eficácia de um cimento de ionômero de vidro fotopolimerizável (vitrebond) para a colagem direta de braquetes ortodônticos em nivelamento 4×2. Rev Dent Press Ortodon Ortoped Facial, Maringá, v. 4, n. 1, p. 31-44, jan./fev. 1999.

29. SILVA FILHO, O. G. et al. Programa supervisionado de motivação e instrução de higiene e fisioterapia bucal em crianças com aparelho ortodôntico. Rev USP, São Paulo, v. 4, n. 1, p. 11-19, jan./mar. 1990

30. SOUZA, F. M. et al. Prevenção de cáries e doenças periodontais em Ortodontia corretiva: métodos simples para serem usados no consultório. Ortodontia, São Paulo, v. 27, n. 3, p. 87-92, set./ dez. 1994.

31. SOUZA M M - FALCÃO A F P. ARAÚJO T M. Higiene bucal no paciente ortodôntico. Rev Fac Odontol Univ Fed Bahia, Salvador, v. 18, p. 60-7, jan./jun. 1999.

32. ZACHRISSON. B. U. Gingival condition associated with orthodontic treatment II. Histologic findings. Angle Orthod, Appleton, v. 42, no. 4, p. 352-7, Oct. 1972.

33. ZACHRISSON, B. U. Oral hygiene for orthodontic patients: current concepts and pratical advice. Am J Orthod, St. Louis, v. 66, n. 5, p. 487-97, Nov. 1974.
Endereço para correspondência

Kelly Polido Kaneshiro Olympio

R. Marcondes Salgado, 17-71 - BI. 02 - Ap. 22 - Vila Antárctica

CEP: 17.013-231 - Bauru /SP

E-mail: kellypko@yahoo.com.br 